\title{
BIR HEYKELIN NIYETi ÜZERINE
}

\section{ON THE INTENTION OF A SCULPTURE}

\author{
Ömer Emre Yavuz*
}

\section{Öz}

Bu çalışmada; heykeltıraş Ümit Öztürk'ün Küçük Hanımefendi filminden yola çıkarak gerçekleştirdiği, Fenerbahçe sahilinde yer alan heykel grubu, sanatçısının ya da izleyicilerinin düşünceleri ya da niyetleri göz ardı edilerek sadece heykelin göstergeleri ışı̆̆ında yorumlanmaktadır. Bu yorumlama heykelde olanlar (in praesentia) ve olmayanlar (in absentia) arasındaki semantik ilişkiye dair sorulan beş soruya verilen yanıtlarla yapılmaya çalışılmıştır.

Anahtar Kelimeler: Heykel, Yorum, Görsel Ideoloji, Teatrallik.

\section{Abstract}

In this study, the group of sculpture realised by sculptor Ümit Öztürk, which he built under the insipation of the movie "Küçük Hanımefendi" and placed in the shore of Fenerbahçe, has been interpreted mainly on the signifiers of the work, without taking into account the consideration or the intention of the artist. This interpretation has been intented to cover with the answers to the five queries about the semantic relationship of what is present (in praesentia) and absent (in absentia) on the sculpture.

Keywords: Sculpture, Interpretation, Visual Ideology, Theatricality.

\section{Giriş}

Bu çalışma, Heykeltıraş Ümit Öztürk'ün Fenerbahçe sahilindeki Küçük Hanımefendi filminden yola çıkarak gerçekleştirdiği heykel grubu hakkında, semantik bir temellendirme amacıyla kaleme alınmıştır. Söz konusu heykele dair çözümlemeler, sanat eleştirisi kapsamında ele alınarak, U. Eco, M. Foucault, J. P. Sartre, N. Hadjinikolaou, M. Fried, R. E. Krauss ve G. E. Lessing gibi kuramcıların metinleri ile ilişkilendirilmiştir.

\section{Küçük Hanımefendi Heykeli}

“Küçük Hanımefendi 53 yıl sonra Kadıköy'de" diye yazıyordu, Kadıköy Life Dergisi'nin 2 Ocak 2017 tarihli sayısında çıkan bir haberde. Haberin konusu: Fenerbahçe sahiline yerleştirilen, yönetmenliğini Nejat Saydam'ın yaptığı, 1961 yapımı Küçük Hanımefendi filminin oyuncularından bazılarının yer aldığı bir heykel grubu idi. Bu grup, filmin oyuncularından Ayhan

Olgu Sunumu // Başvuru tarihi: 25.02.2020 - Kabul tarihi: 14.06.2020.

*Dr. Öğr. Üyesi, Mimar Sinan Güzel Sanatlar Üniversitesi, Güzel Sanatlar Fakültesi, Heykel Bölümü, omer.emre.yavuz@msgsu.edu.tr, https://orcid.org./0000-0002-1404-4739. 
Işık, Belgin Doruk, Sadri Alışık ve bir boom operatöründen oluşan dört figür, bir kamera, bir rejisör koltuğu, bir film spotu ve filmin afişinin yer aldığı bir panodan oluşmakta (Görsel 1). Bu heykel, neredeyse ilk bakışta, üzerine düşünülecek pek bir şey olmadığı hissini uyandırır. Her şey göründüğü gibidir ve apaçık ortadadır. Bir sinema filmi ve o filmden yola çıkarak oluşturulmuş bir heykel. Bununla birlikte bu heykel grubunun görünen yüzeyinin ardında bir başka anlam bulunabileceğini ileri sürmek istiyorum.

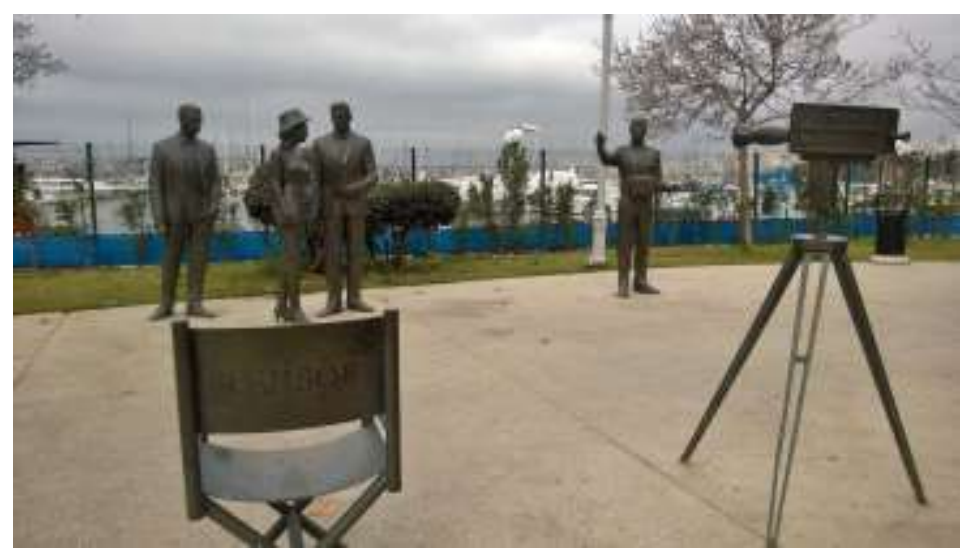

Görsel 1. Ümit Öztürk, Küçük Hanımefendi, 2017, Bronz, Fenerbahçe Sahili.

Umberto Eco Yorum ve Aşırı Yorum'da yazınsal metne dair üç ayrı yorum kuramından bahseder. Eco (2016:33)'ya göre, bir metnin yorumunda, yazarın başlangıçtaki niyeti olarak tanımladığı intentio auctoris (yazarın niyeti) ve "metni ne yapıp edip kendi amacına hizmet eder şekle sokan" intentio lectoris (okurun niyeti) dışında üçüncü bir olasılıktan yani intentio operis' den (metnin niyeti) söz edilebilir. Eco, konuşmasında bu niyetlerden hangisinin geçerli bir yorum olacağı üzerinde durmaktadır. Bu bağlamda, söz konusu heykelin, heykeltıraşının eserde anlatmak istediğinden bağımsız bir niyetinin olup olamayacağı ve eğer var ise bu niyetin ne olduğu, heykeli yorumlama ve dolayısıyla anlamlandırma açısından temel bir sorun olarak karşımıza çıkar. Eco'dan yola çıkarak, mesele yapıt merkezli (intentio operis) bir okuma denemesi olarak ele alındığında, doğal olarak böyle bir okumada yol gösterici olması bakımından Eco'nun, metnin [bu çalışma özelinde heykelin] niyeti hakkındaki sözlerine başvurmak gerekir. Şöyle diyor Eco: “Metnin niyeti metnin yüzeyince sergilenmez." "Dolayısıyla, metnin niyetinden ancak okurun bir tahmininin sonucu olarak söz edilebilir. Okurun girişimi, temel olarak metnin niyeti hakkında bir tahminde bulunmaktan ibarettir”(Eco, 2016:72). O 
halde, heykeltıraş Ümit Öztürk tarafından yapılan ve Fenerbahçe sahilinde yer alan Küçük Hanımefendi heykel gurubunun yüzeyince sergilenmeyen niyeti hakkında bir tahminde bulunabilmek için, öncelikle, heykelde olanlar (in praesentia) ve olmayanlar (in absentia) arasındaki semantik ilişkiye dair akla gelen bazı soruları cevaplamaya çalışalım.

1. Bu heykel grubu bir anıt mı?

2. Heykeli oluşturan ve filmin başrol oyuncularının olduğu üç kişi dışında kalan tek figür neden bir boom operatörü?

3. Filmin yönetmen (rejisör) koltuğu neden boş duruyor?

4. Filmin ışıkçısı ve kameramanı neden yok?

5. Neden Küçük Hanımefendi filmi?

Illk olarak bu heykel grubunun bir anıt olup olmadığını, 1960'lardan günümüze heykel sanatının dönüşümünü ortaya çıkaran modelin yazarı Rosalind Krauss'un ünlü makalesi "Sculpture in the Expanded Field"den (Mekâna Yayılan Heykel) yola çıkarak cevaplamaya çalışalım. Krauss: "Yine de ben heykelin ne olduğunu gayet iyi bildiğimizi söyleyeceğim. Bildiğimiz şeylerden biri de bunun evrensel değil, tarihsel sınırları olan bir kategori olduğudur." “Öyle görünüyor ki; heykel mantığı anıt mantığından ayrılamaz. Bu mantık sayesinde heykel anma işlevi gören bir temsildir. Belli bir yere oturur ve bu yerin anlamı ya da kullanımı hakkında simgesel bir dille konuşur" (Krauss, 2002:103). Krauss (2002:103)'a göre böylesi anıtlar "temsil ve işaretleme mantığıyla bağlantılı olarak işlev" görür ve "kaideleri, gerçek yer ile temsil edici gösterge arasında bir aracılık işlevi gördükleri için yapının önemli birer parçasıdır". Böyle bakıldığında, Küçük Hanımefendi heykel düzenlemesi bağlamında, eserin temsil yönünden bir anıt özelliği göstermesine karşın hem bir yeri işaretlemiyor oluşu, (heykel, filmin çekildiği mekânlardan birinde yer almıyor) hem de kaidesinin olmayışı bağlamında anıt işlevi görmediği söylenebilir. Eğer bu heykel bir anıt değil ise, yine Rosalind Krauss'dan yola çıkarak anıt mantığının zayıflaması sonrasında, anıtın negatif durumu olan, zamansal ve mekânsal temsil projesinden kopmuş modernist bir heykel olduğu ileri sürülebilir mi? Şöyle ki: Krauss (2002:103), kaidenin gerçek ve temsil edici gösterge arasında bir aracılık işlevi gördüğünü söylerken kaideden inen figürün de "kaideyi fetişleştirerek, onu kendi bünyesine katmak için 


\section{SDÜ ART-E}

Güzel Sanatlar Fakültesi Sanat Dergisi

Haziran'20 Cilt:13 Sayı:25

ISSN 1308-2698

aşağıya uzan[dığından] ve bulunduğu fiili yerden uzaklaşı[p]; kendi malzemelerini ve inşa ediliş sürecini temsil ederek kendi özerkliğini betimle[diğini] ve bunun da heykeli işlev bakımından yersiz ve büyük ölçüde kendine gönderen katışıksız bir işaret ya da kaide olarak tanımla[dığından]" bahseder. Dolayısıyla; söz konusu heykelin, diğer özellikleri dışında, kendi malzemelerini ve inşa ediliş sürecini temsil etmediği için, modernist bir heykel olarak tanımlanması da olanaklı değildir. Bu bağlamda heykelin niyetinin ne olduğunu biraz daha netleştirmek için makalenin başında belirlenen sorulara devam edilebilir.

2. 3. ve 4. sorulardan yola çıkılacak olursa, heykel grubunda neyin olup neyin olmadığı bu heykeli anlamlandırmada bize yol gösterecektir. Öncelikle, bu heykelin figüratif bir heykel olduğu göz önünde bulundurulduğunda, heykelde yer alan figürlerin, heykelde olanlar ve olmayanlar hakkında ne söylediğine bakmak gerekir. İlk bakışta, heykelde yer alan figürlerin, filmin başrol oyuncuları olan Ayhan Işık, Belgin Doruk, Sadri Alışık ve boom operatörü olduğu açıkça görülmektedir. Elbette, bu filmden dolayısıyla da oyuncularından haberi olmayan bir izleyici için böyle bir açıklıktan söz edilemez. Böyle bir izleyici (en azından Türkçe bilen) sadece bir film seti görecek ve eğer isterse kompozisyonda yer alan film afişine bakarak bilgi edinebilecektir. Her halükarda izleyici oyunculara dair bir bilgi edinemese bile, bunun bir film setini temsil ettiğini ve boom operatörü ${ }^{1}$ ile filmin oyuncuları arasında bir ayrım yapabileceğini düşünüyorum. Dolayısıyla da konuya dair bir fikri olmasa da en azından kamusal alanda yer aldığı için muhtemelen önemli bir film olduğunu ve oyuncuların filmin hatırlanması bağlamında bir temsil işlevi gördügünü tahmin edebilecektir. O halde, yukarıda da belirttiğimiz kameramanı olmayan bir kamera, boş rejisör koltuğu, ışıkçının olmadığı spot, filmin afişinin bulunduğu pano ve boom operatörünün bu temsiliyet ilişkisinde rolünün ne olduğuna bakalım. Şöyle bir düşünce geliştirilebilir mi? Bu sahne, film çekimine kısa bir ara verildiği, yönetmen, kameraman ve ışıkçının alelacele setten ayrılmış oldukları ancak oyuncuların ve boom operatörünün setten ayrılmadığı bir özel (an)ı temsil etmektedir. Oysa, G. E. Lessing, Laocoon (Laokon) isimli

\footnotetext{
1 Burada açıklık getirilmesi gereken bir diğer nokta da, aslında filmin sesli çekilmediği, oyuncuların seslerinin sonradan dublaj yoluyla eklendiği ve bu sebeple de bir boom operatörünün çekimde yer almasının mümkün olmayışıdır. Heykeltıraşın film hakkında derinlemesine bir araştırma yapmadığı anlaşılmakla birlikte, konumuz açısından bu eksikliğin heykelin niyeti konusunda bir önemi olduğu söylenemez. Aksi takdirde film çekiminde ne tür bir kamera ve ışıklandırma kullanıldığı, sette gerçekten arkasında rejisör yazan bir koltuğun bulunup bulunmadığının da değerlendirilmesi gerekirdi.
} 


\section{SDÜ ART-E}

Güzel Sanatlar Fakültesi Sanat Dergisi

kitabında, "san'atkâr herhangi bir anı gelişigüzel seçmez; lâkin en zengin (an)ı seçer, en zengin an ise muhayyelimize serbest bir saha bırakan andır" diyerek, heykeltıraşın, böyle gelişi güzel bir anı seçmeyeceğini (seçmemesi gerektiğini) vurgular (Lessing, 1935:30). O halde, eğer film setine dair bir heykel yapılmış ise, heykeltıraşın o seti anlatacak en zengin an'ı seçmesi gerekmektedir. Bu durumda, en zengin an'ın, yönetmenin, ışıkçının, kameramanın da sette bulunduğu bir an olması daha uygundur. Dolayısıyla; heykeli anlamlandırmak ancak, teknik olarak kamerayı ya da ışığı nesnel olarak ayakta tutmak için bir insana gerek olmayışı; boom çubuğunun kendi başına ayakta duramayışı ve kameranın filmin başrol oyuncularına dönük oluşu ile ilişkilendirilerek mümkün olacaktır. Böylelikle heykel, izleyicinin, bir kameraman gibi kameranın vizöründen bakarak, o filmi kendi çekiyormuş gibi yaşamasına ya da boş rejisör koltuğu yine izleyicinin oturarak kendisini filmin yönetmeni gibi hissetmesine yarayacaktır. Heykelin işlevi, dolayısıyla anlamı, izleyicinin yapıta dahil olması ile doğrudan ilişkilidir. Heykel ve izleyici arasındaki bu ilişkiye, gündelik hayatın doğal bir uzantısı haline gelen, fotoğraf ve video gibi medya unsurları da eşlik eder (Görsel 2). Buradan yola çıkarak, heykelin, aynı zamanda, sahneye katılımcı da olan izleyicilerin, gerçek anlamda görüntülenme arzularını uyandırmasına yönelik olarak tasarlandığı da öne sürülebilir (Görsel 3).

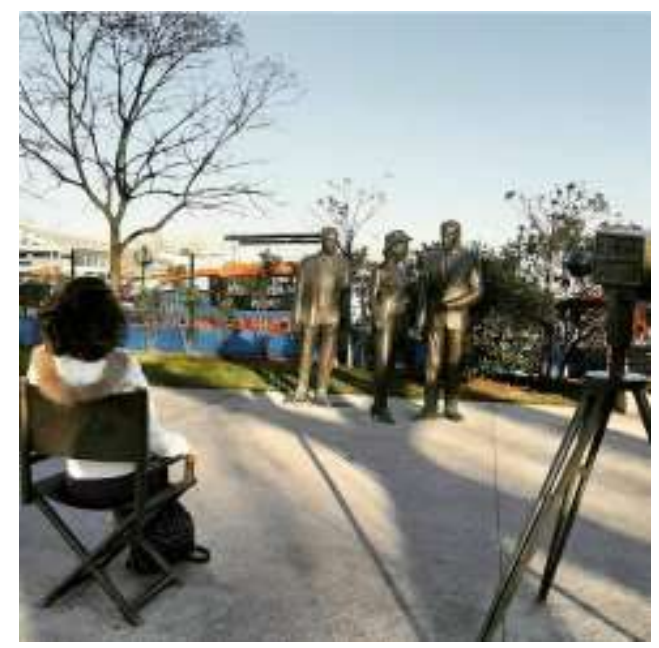

Görsel 2. Ümit Öztürk, Küçük Hanımefendi, 2017, Bronz, Fenerbahçe Sahili. 


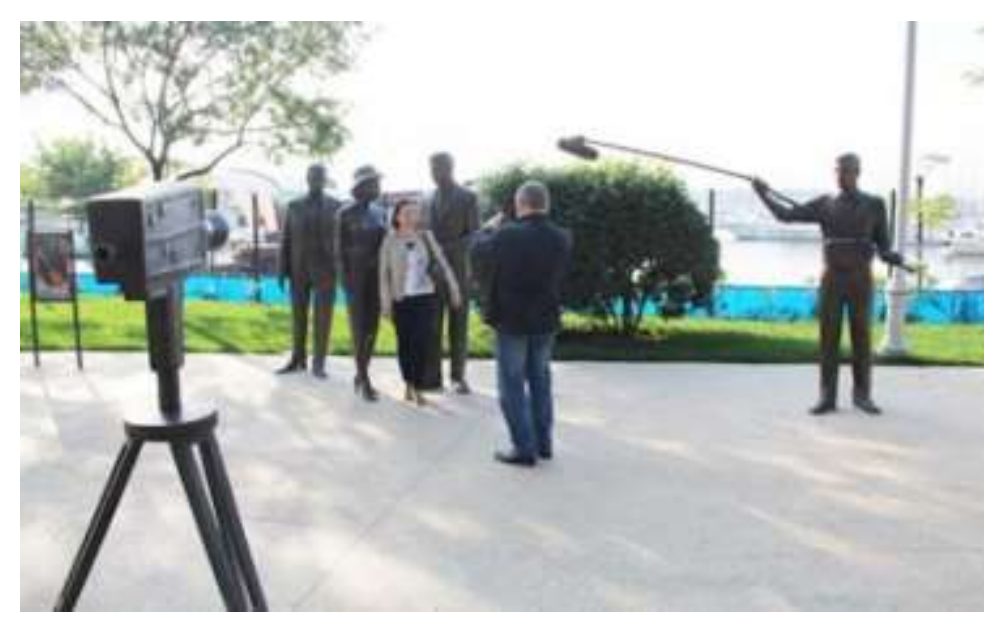

Görsel 3. Ümit Öztürk, Küçük Hanımefendi, 2017, Bronz, Fenerbahçe Sahili.

Demek oluyor ki: Heykel, figüratif bir anlayışla yapılmış, bir filmin başrol oyuncularının yer aldığı kaidesi olmayan bir kompozisyon olarak ve izleyicinin sanki o filmin yönetmeni, oyuncusu, kameramanı ya da ışıkçısı olarak fotoğrafına dâhil olabileceği interaktif bir düzenlemedir. Dolayısıyla; izleyici ya sadece eseri uzaktan izleyecek ya da yapıta dahil olacaktır. Peki; izleyici hem yapıtı izleyen hem de onun bir parçası olmaz mı? Bunu resim sanatına ilişkin bir örnek üzerinden cevaplamak için, seyircinin, kendisini resimdeki karakterlerden biri olarak hissedebildiği, Velasquez'in meşhur Las Meninas (Nedimeler) tablosundan yola çıkılabilir. Bilindiği gibi, Las Meninas resminin karşısına geçen izleyici, resme, resmin içindeki aynaya yansıyan Kral ve Kraliçenin durduğu noktadan bakmaktadır. Bu resme bakan kişi, hem resmin içinde bir karakter hem de resmin izleyicisi olma konumundadır. Michel Foucault, Kelimeler ve Şeyler'de bu durumu: "Las Meninas, bakanın bakılan olduğu ve tablonun kişilerinin arasına katıldığı tek resimdir; ayna kral ile kraliçenin görüntüleriyle birlikte, bizimkini de yansıtmak durumundadır" (Foucault, 2016:9) diye yorumlar. Burada şöyle bir soru akla gelebilir: resimde mümkün olmayan, bu türden bir yanılsama acaba heykelde mümkün mü? Bu soruyu Sartre'ın Giacometti hakkında yazdığı "The Search for the Absolute, in Alberto Giacometti" adlı denemesinden yola çıkarak cevaplamaya çalışalım. Söyle söylüyor Sartre: "Resimde üçüncü boyutun gerçek dışılığı fiilen diğer ikisini de gerçek dışı kılar. Dolayısıyla figürlerin benden uzaklığı hayalidir. Yaklaşırsam figürlere değil tuvale yaklaşırım. Burnumu bile koysam onları yirmi adımda görebilirim. Çünkü ancak ilk ve son kez olarak yirmi adımda var olmaya başlar" (Sartre, 1948). "Yontucular bu temel gerçekleri fark etmediler. Çünkü üç boyutlu bir uzamda 
gerçek mermerin üzerinde çalışıyorlardı. Sanatlarının ürünü hayali bile olsa onu gerçek bir mekânda yansıtmanın olanaklı olduğunu düşündüler" (Sartre, 1948). Buradan da anlaşılacağı üzere; resim ve heykel arasında temel bir fark vardır. Bu fark resmin bir yanılsama düzlemi oluşudur. Dolayısıyla Sartre'dan yola çıkarak, Velasquez'in, Las Meninas resminde yaptığı metaforik yanılsamanın yani izleyiciyi resmin bir karakteri gibi hissettirmenin, heykel sanatında uygulanmasının mümkün olmadığı söylenebilir. Yanılsamanın olmayışı, bu eserin, izleyicinin fiilen içinde yer almadan kendisini gerçekleştiremeyeceği anlamına gelmektedir. Ayrıca bu eserin izleyiciye kendini açması, izleyicinin içinde yer almadan gerçekleşmesinin mümkün olmayışı eserin teatralliği ile de ilişkilendirilebilir. Daha önce Krauss'tan yola çıkarak heykelin kaidesi olmayışı, kendi malzemelerini ve inşa ediliş sürecini temsil etmeyişi bağlamında modernist bir heykel olmadığını söylemiş̧tik. Şimdi de Michael Fried'dan yola çıkarak heykelin izleyici ile olan ilişkisinin modernist heykel açısından ne anlama geldiğini açıklamaya çalışalım. Michael Fried "Art and Objecthood" (Sanat ve Nesnelik) adlı makalesinde teatralliğin anlaşılmasını, sanatsal çalışma ile seyircinin ilişkisine dayandırır. Sanatsal çalışma seyirciye ne kadar yönelir, onunla flört eder ya da onu kendine katarsa o kadar teatraldir. Fried'a göre: Tiyatro doğası gereği 'teatral durum' denilen şeyden hiçbir zaman kaçınamazken, resim ve heykel sanatları formları/doğaları gereği bundan (izleyiciye muhtaç teatrallik açmazından) kaçınabilirler (Sezgin, 2010). Bu anlamda teatrallik, sanatın modern ya da özerk olabilmesi için kendini arındırması gereken bir şeydir. Böylelikle, bu düzenlemenin izleyiciye muhtaç oluşunu teatrallik ile ilişkilendirerek, modernist bir heykel olmadığının bir kez daha altını çizmiş oluyoruz.

Son olarak, Türk sinema tarihinden bir film canlandırılacaksa neden Küçük Hanımefendi? Bu soru bizi acaba Küçük Hanımefendi filmi Türk Sinemasının bir baş yapıtı olup olmadığı konusunda düşünmeye iter. Film hakkında yaptığım araştırma bunun öyle olmadığını söylüyor. Öncelikle, filmin uyarlandığı romanın yazarı Muazzez Tahsin Berkand’ın Türk pembe romanlarının öncüsü olduğunu belirtmekte fayda görüyorum. 1961'de çekilen Küçük Hanımefendi'nin bu serinin ilk filmi oluşu, daha sonrasında, Küçük Hanım Avrupa'da (1962), Küçük Hanımın Kısmeti (1962), Küçük Hanımın Şoförü (1962), Küçük Hanımın Şoförü (1970) (Aynı kadro), Küçük Hanımefendi (1970) (Hülya Koçyiğit, Kartal Tibet) filmlerinin çekilmiş olması 
filmin bir pembe dizi olduğu düşüncemizi desteklemektedir (Görsel 4). Elbette burada anlatılmaya çalışılan filmin türüne göre iyi bir film olup olmadığı değil. Tür olarak heykeli yapılmaya aday olup olmadığıdır. Eğer sinema tarihimiz adına bir film kamusal alanda heykelleştirilecek ise bu filmin seçilmesinin nedenleri anlaşılamamaktadır.
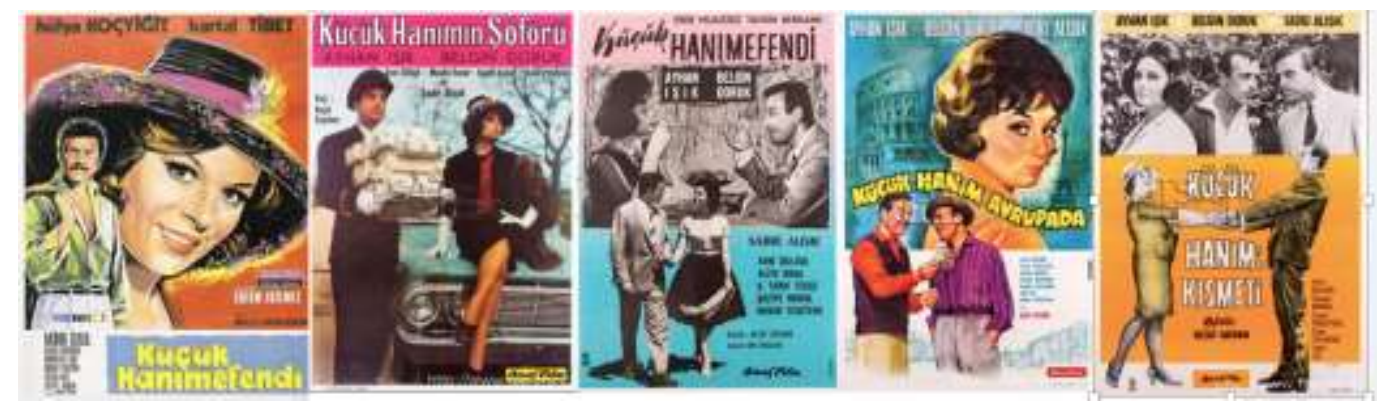

Görsel 4. Küçük Hanımefendi Film Afişleri

Belki, bu seçimin, dolayısıyla da heykelin, görsel ideoloji bağlamında ne ifade ettiğine bakarak bir çıkarımda bulunulabilir. Nicos Hadjinicolaou Sanat Tarihi ve Sınıf Mücadelesi adlı kitabında bir sanat yapıtının ideolojisinin, görsel bir ideoloji olduğunu savunur. Ona göre "Görsel ideoloji, bir tablonun biçimsel (formel) ve izleksel (tematik) öğelerinin her özgül (spesifik) durumdaki birleşme tarzlarıdır. Bu, toplumsal bir sınıfın tümel ideolojisinin tikel bir biçimidir". (Hadjinicolaou, 1987:130) Hadjinicolaou, bu görsel ideolojinin, olumlayıcı ve eleştirel olmak üzere iki şekilde gerçekleştiğinden bahseder. O halde, Küçük Hanımefendi heykelini olumlayıcı görsel ideoloji mi yoksa eleştirel görsel ideoloji olarak mı değerlendirmeliyiz. Bunu anlayabilmek için Hadjinicolaou’nun bunları nasıl tanımladığına kısaca göz atalım. "Olumlayıcı görsel ideoloji, bir yapıtın görsel ideolojisiyle o resmin [heykelin] kimi ögelerinin ait olduğu öbür ideoloji tipleri arasındaki ilişkide göze çarpan bir çelişmenin bulunmaması anlamına gelir. Bu olumlu, karşıt-olmayan ilişki, görsel ideolojiler aracılı̆̆ıla öbür ideoloji tiplerini yüceltecek kadar ileri gidebilir" (Hadjinicolaou, 1987:196). "Olumlayıcı görsel ideoloji, bir konuya yaklaşımları, bir gerçekliğin süslenip püslenmesinden ya da bir gerçekliğin varoluşunun yalın olumlanmasından, gerçekliğin yüceltilmesine değin değişen bireysel yapıtlarda dile getirilir. Bu olumlayıcı görsel ideoloji, öbür görsel ideolojilere ait öğelerin bu bireysel yapıtların bütünsel yapısı içinde birbiriyle çatışma halinde olmayan bir ilişki içinde bulundukları zaman ortaya çıkar" (Hadjinicolaou, 1987:201). “Buna karşılık, eleştirel görsel ideoloji, bir yapıtın görsel ideolojisinin 


\section{SDÜ ART-E}

Güzel Sanatlar Fakültesi Sanat Dergisi

Haziran'20 Cilt:13 Sayı:25

ISSN 1308-2698

kimi ögeleri yapıtta bulunan diğer görsel olmayan ideoloji türlerine yönelik eleştirel bir işlev gördüğü anlamına gelir"(Hadjinicolaou, 1987:196). Bu bağlamda; Türk Sineması'nın eski pembe dizilerinden Küçük Hanımefendi filminin, heykelinin yapılması için seçilmesi ile sanatçının bu heykeli bir eğlence unsuru, bir tür hatıra fotoğrafı panosu işlevi görecek şekilde gerçekleştirmiş olduğu düşünüldüğünde; yapıtın görsel ideolojisiyle, toplumun kolektif görsel ideolojisi haline gelen görsel medya ideolojisi arasında hiçbir çelişmenin bulunmadı̆̆ını ve böylelikle de olumlayıcı bir görsel ideolojisi olduğu sonucuna ulaşılabilir.

\section{Sonuç}

Ülkemizde kamusal alanda yer alan heykellerle ilgili pek çok araştırma olmakla beraber, pek az eleştirel yaklaşım var. Kamusal alanda yer alan heykeller ile ilgili yazılı eleştirilerin büyük bir çoğunluğunun da toplumun ahlaki değerleri ile örtüşmediği için ileri sürüldüğü ve sadece beğeni düzeyinde kaldığı da söylenebilir. Bu metinde, sanatçının ya da dökümcünün atölyesinden çıkarak kamusal alana konulduğu ilk andan itibaren, heykeltıraşın niyetinin bir önemi kalmadığı düşüncesi ile sadece heykelin, izleyiciye neler ilettiğine odaklanılmıştır. Bununla birlikte, bu çalışmada heykelin olabilecek her yönü ile incelendiği de söylenemez. Aynı heykel çok faklı şekillerde de yorumlanabilirdi. Ancak, heykelin niyeti doğrultusunda tüm söylenebileceklere odaklanarak bütünsel bir yaklaşım elde edilmeye çalışıldı. Bu bağlamda sanatçıya değil de heykele soru sormak daha uygun görünmektedir. Çünkü heykelin niyetini sanatçının ve okurun niyetinden ayırmak onu yorumlamak için elimizdeki en uygun çözümdür.

Bu noktada, ele alınan yorumlama yöntemi doğrultusunda heykele yönlendirilen sorular neticesinde elde edilen bulgular şöyle özetlenebilir. Bu heykel bir ne bir anıt heykeli ne de modernist bir heykeldir. Heykelin Postmodern bir heykel olmadığı da söylenebilir. Çünkü, “Postmodernizm'in stratejilerinin başında çifte kodlama gelir. Alanın uzmanlarından ve halktan oluşan iki ayrı seyirci kitlesi için de bir çekim alanı yaratır. Umberto Eco, bu çifte kodlamayı Postmodern edebiyat için de önermiş ve uygulamıştı. Gülün Adı (1980), hem popüler kitlenin hem de Ortaçağ uzmanlarının aynı anda ilgisini uyandırabilmişti ${ }^{2 \prime}$. Metinde heykelin görsel ideolojisinin olumlayıcı olduğu saptaması ile bir bakıma, iki ayrı seyirci için bir çekim alanı oluşturmadığı yani Postmodern stratejilerle temelde ayrıldığı da ifade edilmiş oluyor. Herhangi bir dönemselleştirme

\footnotetext{
${ }^{2}$ Bkz. https://kavrakoglu.com/cagdas-sanata-varis-172-postmodern-sanat-6-sanat-bilgi-manifesto-felsefe-iliskisi/ Erişim tarihi: 29.05.2020.
} 
yapılamıyor, hatta anıt olmasa da geleneksel heykele özgü temel ögeler arasında yer alan, heykeltıraşın en zengin an'ı seçmediği de görülmektedir. Heykel, izleyicinin içinde yer alarak kendini bir rejisör, kameraman ya da ışıkçı gibi görmesini amaçlayarak bir gösteriye dönüşmüştür. Anlaşılıyor ki, gördüğümüz nesneye heykel niteliği kazandıran şey ya da izleyicinin onu heykel olarak görmesi sadece belli toplumsal uylaşımlara dayanmaktadır. Oysa, kamusal alanda gördüğümüz bronzdan dökülmüş, taştan yontulmuş her figür çalışması özünde bir heykel değildir. Her ne kadar yapan kişi bir heykeltıraş olsa da.

\section{Kaynakça}

Eco, U, (2016). Yorum ve Aşırı Yorum, (çev.) Kemal Atakay, İstanbul, Ayrıntı Yayınları.

Foucault, M. (2016). Kelimeler ve Şeyler, (çev.) Mehmet Ali Kılıçbay, İstanbul, İmge Kitabevi.

Frıed, M. (1998). Art and Objecthood: Essays and Reviews, University of Chicago Press.

Hadjinicolaou, N. (1987). Sanat Tarihi ve Sınıf Mücadelesi, (çev.) M. Halim Spatar, İstanbul, Kaynak Yayınları.

Krauss, R. E. (2002). Mekâna Yayılan Heykel, çev. Tuncay Birkan, Sanat Dünyamız, Kış (Heykel Özel Sayısı), İstanbul, Yapı Kredi Yayınları, Sayı 82.

Lessing, G. E. (1935). Laocoon (Laokon), (çev.) Suut Kemal Yetkin, Dün ve Yarın Tercüme Külliyatı.

Sartre, J. P. (1948). "The Search for the Absolute", in Alberto Giacometti, New York Pierre Matisse Gallery (Katalog Yazısı).

Sezgin, B. (2010). "Teatrallik Nedir?”, Mimesis Tiyatro / Çeviri - Araştırma Dergisi, İstanbul, Boğaziçi Üniversitesi Yayınevi, Sayı 18.

\section{İnternet Kaynakları}

Kavrakoğlu, F. (2015). Çağdaş Sanata Varis-172-Postmodern Sanat 6 Sanat-Bilgi-ManifestoFelsefe-iliskisi,https://kavrakoglu.com/cagdas-sanata-varis-172-postmodern-sanat-6-sanatbilgi-manifesto-felsefe-iliskisi/ Erişim tarihi: 29.05.2020.

\section{Görsel Kaynakça}

Görsel 1. Ümit Öztürk, Küçük Hanımefendi, 2017, Bronz, Fenerbahçe Sahili, http://merininaynasi.blogspot.com/2016/03/fenerbahce-park.html, Erişim tarihi: 29.05.2020. 
SDÜ ART-E

Güzel Sanatlar Fakültesi Sanat Dergisi

Haziran'20 Cilt:13 Sayı:25

ISSN 1308-2698

Görsel 2. Ümit Öztürk, Küçük Hanımefendi, 2017, Bronz, Fenerbahçe Sahili, https://pictame2.com/media/B8hSOFuneNG/, Erişim tarihi: 29.05.2020.

Görsel 3. Ümit Öztürk, Küçük Hanımefendi, 2017, Bronz, Fenerbahçe Sahili, Ömer Emre Yavuz Arşivi.

Görsel 4. Küçük Hanımefendi Film Afişleri, Türk Sineması Araştırmaları, https://www.tsa.org.tr/Erişim tarihi: 29.05.2020. 